\title{
Measuring mineral dissolution kinetics using on-line flow-through time resolved analysis (FT-TRA): an exploratory study with forsterite
}

\author{
Bart De Baere* ${ }^{*}$ Roger François, K. Ulrich Mayer \\ Department of Earth, Ocean and Atmospheric Sciences, University of British Columbia, 2020-2207 Main Mall, Vancouver, BC V6T 1Z4, Canada
}

\section{A R T I C L E I N F O}

\section{Article history:}

Received 17 March 2015

Received in revised form 22 August 2015

Accepted 26 August 2015

Available online 2 September 2015

\section{Keywords:}

Mineral dissolution

Dissolution rate

Forsterite

Flow-through dissolution

Stoichiometry

Exfoliation

Leached layer

\begin{abstract}
A B S T R A C T
We explore the applicability of on-line flow-through time-resolved analysis (FT-TRA) to measure mineral dissolution rates, determine dissolution rate parameters, and monitor dissolution stoichiometry under both constant and transient eluent conditions. A custom-built automated flow-through system is used to subject mineral samples to controlled eluent flows of constant or varying composition, and the dissolution products are measured online with a quadrupole ICP-MS. Because forsterite dissolution has been extensively studied, this mineral provides an ideal benchmark to test the approach.

FT-TRA has several advantages compared to the mixed-flow reactors conventionally used to measure mineral dissolution. The mineral dissolution regime (surface vs transport-controlled) can be readily established prior to conducting dissolution experiments, which is important if the goal of the experiment is to determine dissolution rate parameters. Because of the small volume $(25 \mu \mathrm{L})$ of the flow-through reactor, the time to reach steady state concentration in the effluent is shorter and is limited by the intrinsic properties of the mineral, instead of the residence time of the effluent in the reactor. For minerals reaching steady-state dissolution rapidly, dissolution rate parameters (rate constant(s) and reaction order(s)) are established in a few hours, allowing for replications, statistical analysis of the results, and investigation of the underlying causes of variability. The experimental set-up can be adapted for minerals that require longer periods of time to reach steady-state dissolution. In addition, FTTRA lends itself particularly well for detailed monitoring of dissolution rates and dissolution stoichiometry under transient conditions. For forsterite dissolution under acidic conditions, preferential release of $\mathrm{Mg}$ when $\mathrm{pH}$ transits to lower values, and preferential release of $\mathrm{Si}$ when $\mathrm{pH}$ transits to higher values is clearly documented and can be interpreted as indicating changes in the mean depth of the Si-rich surface layer in response to changes in eluent acidity. Episodes of exfoliation of the Si-rich surface layer can also be identified, providing a means to study one of the potential rate limiting steps for $\mathrm{CO}_{2}$ sequestration by carbonation of olivine. The results presented here indicate that FT-TRA with online ICP-MS analysis could be a useful and multifaceted addition to the toolbox available to study mineral dissolution.
\end{abstract}

(c) 2015 Elsevier B.V. All rights reserved.

\section{Introduction}

Accurate determination of mineral dissolution rates over a wide range of conditions ( $\mathrm{pH}$, temperature, $\mathrm{pCO}_{2}$, etc.) is essential to investigate a wide variety of environmental processes. However, mineral dissolution rates measured in different laboratories can differ by several orders of magnitude (e.g. Rimstidt et al., 2012), and this problem is compounded by the fact that methods used to measure mineral dissolution rates tend to be labor intensive and time consuming. Methods capable of rapidly generating data on mineral dissolution rates would be beneficial to study the factors underpinning the variability of this process and to better constrain random errors. Likewise, methods providing information on dissolution rate and stoichiometry under non-

\footnotetext{
* Corresponding author.

E-mail addresses: b.debaere@alumni.ubc.ca (B. De Baere), rfrancoi@eos.ubc.ca (R. François), umayer@eos.ubc.ca (K.U. Mayer).
}

steady-state or transient conditions would help elucidate the factors controlling mineral dissolution. This study uses forsterite to explore the applicability of "flow-through time resolved analysis" (FT-TRA) with on-line measurement of dissolution products by inductively coupled plasma mass spectrometry (ICP-MS) to measure mineral dissolution rate and stoichiometry under constant and transient eluent conditions. Forsterite was chosen because its dissolution kinetics have been well characterized in a number of laboratory studies (Rimstidt et al., 2012), providing a robust benchmark to assess the results obtained with the new approach. In addition, its dissolution rate below pH 6 is relatively rapid and controlled by the activity of protons, resulting in a simple linear relationship between the logarithm of the surface normalized dissolution rate and $\mathrm{pH}$ (e.g. Chen and Brantley, 2000).

In the proposed flow-through system, the amount of mineral subjected to dissolution $(10-20 \mathrm{mg}$ ) and the volume of the reactor $(25 \mu \mathrm{L})$ are much smaller than for the mixed flow reactors commonly used to estimate mineral dissolution rate parameters, and the resulting 
ratio of mineral surface area to reactor volume (A/V) much higher. Because of its very small volume, much shorter eluent residence times can be achieved in the reactor (seconds vs. hours), which is key to reducing the time needed to reach steady state dissolution. On-line analysis of the dissolution products by ICP-MS provides real-time information on the evolution of the mineral dissolution conditions (steady-state or not) and stoichiometry (congruent vs incongruent dissolution). In addition, ICP-MS low detection limits and wide dynamic range allow for the simultaneous measurement of major and minor elements released during dissolution. Low detection limits could also facilitate the study of minerals dissolving very slowly. The goals of this study are to establish whether this approach can provide a means to measure mineral dissolution rates under a range of conditions more rapidly than with mixed flow reactors, whilst also providing insights into mineral dissolution under transient eluent and non-steady-state mineral surface conditions.

\section{Background}

Most dissolution rate studies (including the present study) are conducted under "far-from-equilibrium" conditions. Under these conditions, mineral dissolution is affected by a number of intrinsic and extrinsic parameters (e.g. Fischer et al., 2014). Intrinsic parameters include mineral composition, crystal structure and surface nanoscale features (terraces, step edges, kinks, screw dislocations). Extrinsic parameters consist of temperature, the composition of the fluid in which the mineral is dissolving ( $\mathrm{pH}$, degree of undersaturation, ionic strength, $p \mathrm{CO}_{2}$, etc.) and the dissolution regime (surface vs. transport-controlled). Rate laws most commonly used to describe the dissolution rate of minerals under far-from-equilibrium, surface controlled conditions can be generalized by Eq. (1) (e.g. Lasaga, 1984):

$R_{f}=\left(\frac{m}{m_{0}}\right)^{n} A \sum_{i=1}^{N_{p}} k_{i} a_{i}^{n_{i}}$

where

$R_{f} \quad$ overall dissolution rate $\left(\right.$ moles s $\left.^{-1}\right)$

$m$ moles of mineral at a given time

$m_{0} \quad$ initial moles of mineral present

$n$ factor that accounts for changes in surface area during dissolution ( $\mathrm{n}=2 / 3$ for single uniformly dissolving spheres and cubes, Appelo and Postma, 2005).

A surface area $\left(\mathrm{m}^{2}\right)$.

$N_{p} \quad$ number of parallel reaction pathways leading to dissolution

$k_{i} \quad$ rate constant associated with aqueous species $i$ (moles $\left.\mathrm{m}^{-2} \mathrm{~s}^{-1}\right)^{*}$

$a_{i} \quad$ activity of aqueous species $i$

$n_{i} \quad$ reaction order

*Assuming that $a_{i}{ }^{n_{i}}$ is treated as a dimensionless term.

For a given mineral, its surface-normalized rate of dissolution $\left(R_{f} / \mathrm{A}\right.$; moles $\mathrm{m}^{-2} \mathrm{~s}^{-1}$ ) depends on its intrinsic properties, which dictate the rate constants $\left(\mathrm{k}_{\mathrm{i}}^{\prime} \mathrm{s}\right)$ and reaction orders $\left(\mathrm{n}_{\mathrm{i}} \mathrm{s}\right)$, and the activity of aqueous species that control dissolution $\left(\mathrm{a}_{\mathrm{i}} \mathrm{s}\right)$.

Mineral dissolution rates are most commonly measured in batch reactors or mixed flow reactors. Batch reactors are closed systems in which mineral dissolution is allowed to proceed towards equilibrium. The concentrations of elements of interest are measured as a function of time and fitted to a presumed rate law. In contrast, mixed-flow reactors are open systems in which the solvent and dissolution products continuously flow in and out of the reactor. Measurements are typically made after the reactor has reached steady-state, i.e. when the eluent composition is constant, which is achieved when the rate of element release from mineral dissolution is equal to its rate of removal from the system with the effluent. A key benefit of the mixed flow reactors is that precipitation of secondary minerals can be avoided by removing the dissolution products before they reach saturation in the reactor. Hence, mixed flow reactors have generally been the preferred technique for measuring mineral dissolution rates.

Both batch and mixed flow reactors require a considerable amount of time to conduct the necessary measurements and calculate dissolution rate constants, from a few to 1000 s of hours per experiment covering a single experimental condition (e.g. Brantley and Chen, 1995). Dissolution is typically monitored ex-situ, and a series of experiments needs to be carried out to cover a range in experimental conditions before dissolution rate constants can be calculated. Furthermore, after compiling all available data on forsterite dissolution rate as a function of pH and temperature, Rimstidt et al. (2012) concluded that the standard deviation of dissolution rates measured in different studies is 300-fold, i.e. more than ten times larger than expected from analytical uncertainties alone (Rosso and Rimstidt, 2000). Discrepancies between studies have been mostly attributed to surface normalization, which is generally done using "geometric" surfaces, calculated from mineral grain diameter, or "BET" surface, measured by gas adsorption. These operationally defined surface areas are not necessarily proportional to the "reactive" surface area (White and Peterson, 1990) or the concentration of reactive surface sites that controls the rate of dissolution. The concentration of reactive surface sites may not be uniformly distributed on mineral surfaces and may vary as mineral dissolution proceeds (e.g. Lüttge et al., 2013). Sample preparation (e.g. grinding methods) is another uncontrolled factor that could affect reactive site density and distribution and contribute to the variability in dissolution rate constants estimated in different laboratories.

\section{Materials and methods}

\subsection{Materials}

Forsterite grains were obtained from Ward's Natural Science (item \#491,557). Transparent mineral grains were handpicked, and ground down to a 63-150 $\mu \mathrm{m}$ size fraction. Sample treatment was limited to ultrasonic cleaning with acetone until a clear supernatant was obtained. The sample was dried overnight in an oven at $60^{\circ} \mathrm{C}$. The mineral grains were examined by scanning electron microscopy (SEM), which revealed that they were generally free of adhering fine particles (Fig. 1). The sample had a purity of $98.8 \%$ forsterite (quartz $=0.9 \%$ and pyrite $=0.3 \%$ ), determined by quantitative XRD. Forsterite stoichiometry was established by total digestion and elemental analysis $\left(\mathrm{Mg}_{1.81} \mathrm{Fe}_{0 \cdot 18} \mathrm{Ni}_{0.01} \mathrm{SiO}_{4}\right.$; Fo91). Surface area was measured using multi-point BET (Brunauer et al.,

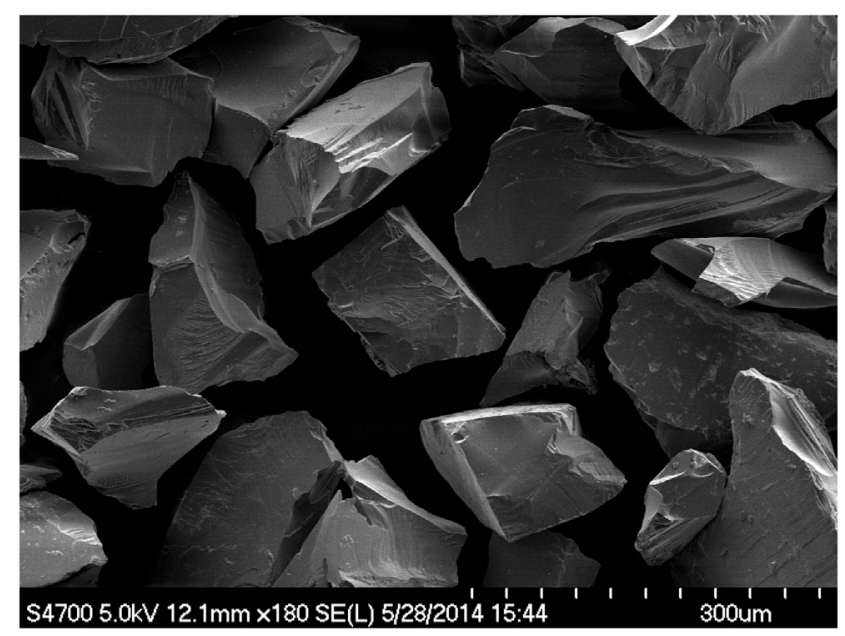

Fig. 1. SEM image at low magnification $\times 180$ of the forsterite sample used in this study, after acetone cleaning. 
1938) with $\mathrm{N}_{2}$ adsorption using a Quantachrome Autosorb-1 surface area analyzer.

\subsection{Flow-through dissolution module}

A flow-through dissolution module was built by simplifying the original design developed by Haley and Klinkhammer (2002). A schematic of the FT-TRA module is shown in Fig. 2. Eluents are pumped from individual bottles (E1-E4) by a Dionex ICS-3000 dual pump (designed using an entirely metal-free (PEEK) flow-path) equipped with time-programmable proportioning valves. The gradient pump was programmed to control the time-dependent composition of the eluent (for the experiment) or standard (for calibration). The isocratic pump continuously supplies an internal standard (indium, in bottle
E5) to correct for instrumental drift associated with the on-line measurement of effluent concentration by Inductively Coupled Plasma Mass Spectrometry (Agilent $7700 \times$ quadrupole ICP-MS). Programming of the gradient pump is done using the Chromeleon ${ }^{\circledR}$ Chromatography Data System. The generated eluent either directly joins the internal standard stream (when running standards) or passes through a flowthrough cell (when running samples) before merging with the internal standard stream. Here, the flow-through cell containing the sample consists of a $13 \mathrm{~mm}$ diameter Millex ${ }^{\circledR}$ syringe filter with a PTFE membrane $(0.2 \mu \mathrm{m}$, Millipore catalog \#SLLGC13NL) mounted between two computer controlled parallel solenoid valves (NResearch, Inc., \#225T092C). Effluent pH measurement with a Bio-Rad DuoFlow inline $\mathrm{pH}$ electrode (Catalog number 760-2040) is optional for dissolution experiments expected to result in measureable $\mathrm{pH}$ changes $(>0.1 \mathrm{pH}$

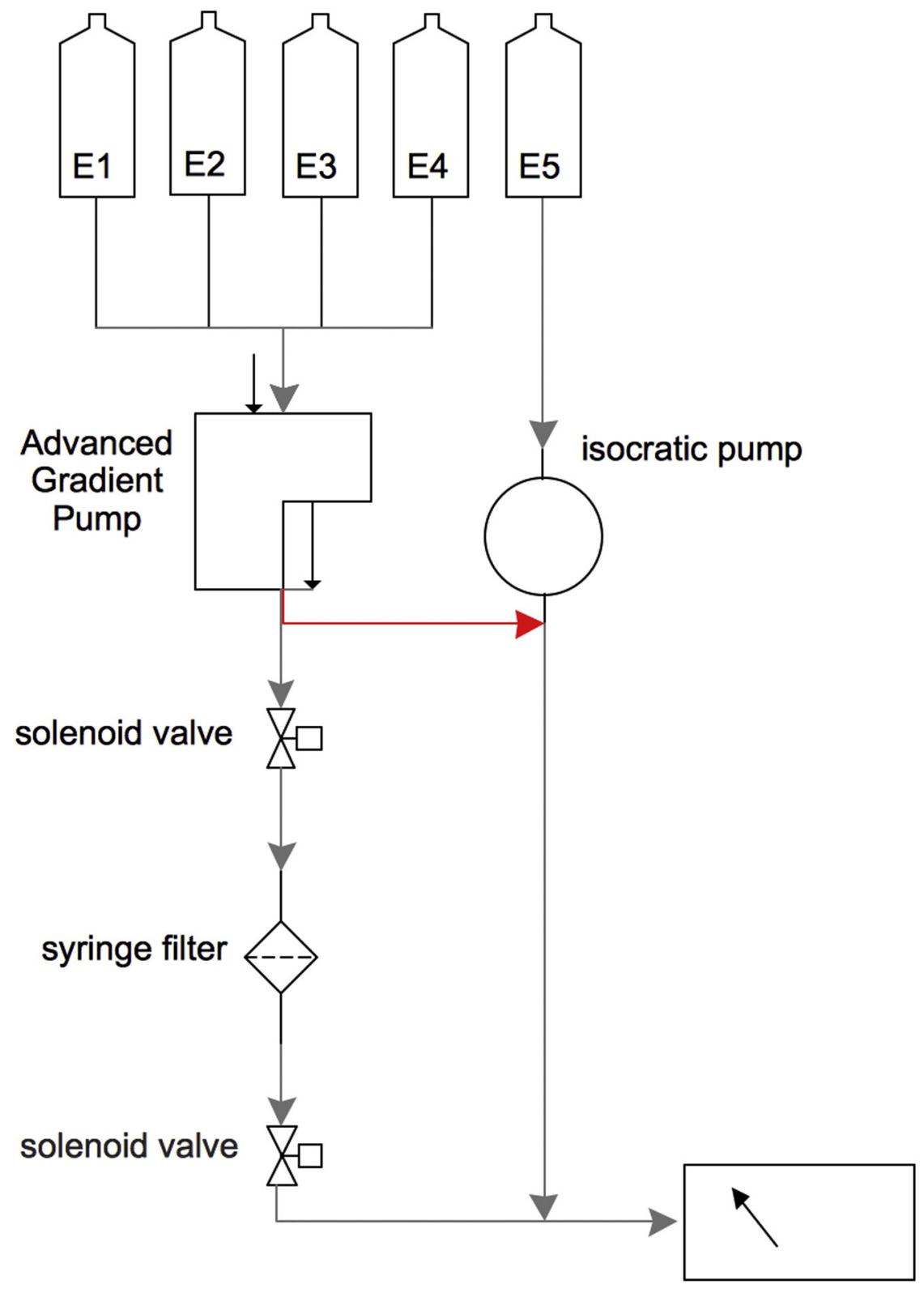

ICP-MS

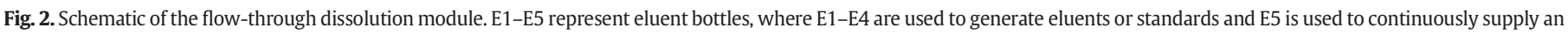

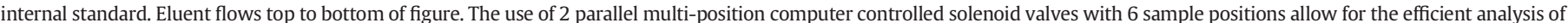

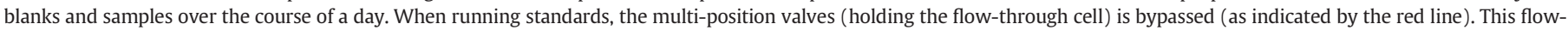

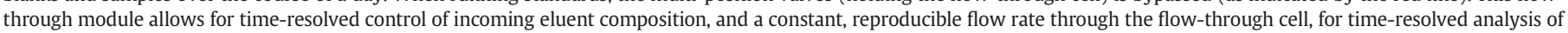
the effluent stream by quadrupole ICP-MS. (For interpretation of the references to color in this figure legend, the reader is referred to the web version of this article.) 
unit). When dissolving forsterite in our experiments, $\mathrm{pH}$ changes were $\ll 0.1 \mathrm{pH}$ unit and thus impossible to record with the present system. The $\mathrm{pH}$ reported in our experiments is the $\mathrm{pH}$ of the incoming solutions.

Forsterite subsamples were weighed on a Mettler Toledo XP6 microbalance, inserted into the upstream side of the filter and continuously exposed to a pre-programmed eluent sequence at room temperature. The eluent was in contact with ambient atmospheric $p \mathrm{CO}_{2}$. The flow rate used in all experiments was $0.7 \mathrm{~mL} \mathrm{~min}{ }^{-1}$ ( $\pm 1.6 \% ; 95 \% \mathrm{CI})$, resulting in an eluent residence time of $\sim 2.1 \mathrm{~s}$ in the reactor, based on a syringe filter internal volume of $25 \mu \mathrm{L}$. The effluent combined with the internal standard was then introduced directly into the plasma of an ICP-MS for time-resolved measurement of ${ }^{24} \mathrm{Mg},{ }^{28} \mathrm{Si}$ and ${ }^{115} \mathrm{In}$.

The main difference between this experimental set-up and mixed flow reactors is the very small size of the reactor and mineral samples, the short residence time of the eluent in the reactor and the short time of contact between eluent and mineral. Mixed flow reactors have to be well mixed because concentration measurements are conducted on a small subsample of the entire volume of the reactor. FT-TRA is not a mixed flow reactor in the sense that the reactor does not need to be well mixed, because the volume of the cell is renewed entirely every $10 \mathrm{~s}(5 \times 2.1 \mathrm{~s})$. On this time scale, mass balance dictates that the elemental concentration of the eluent times flow rate must be equal to the rate at which the element is released by dissolution of the mineral (assuming full exposure of the mineral to the eluent).

\subsection{Measurements of magnesium and silicon concentration in the eluent by on-line quadrupole ICP-MS}

${ }^{24} \mathrm{Mg},{ }^{28} \mathrm{Si}$, and ${ }^{115} \mathrm{In}$ counts per second (cps) were recorded using the time resolved analysis setting on an Agilent $7700 \times$ quadrupole ICP-MS in He-mode. Counts per second obtained were corrected for dilution caused by merging eluent and internal standard streams (eluents and standards had a flow rate of $0.7 \mathrm{~mL} \mathrm{~min}^{-1}$ while the internal standard flow rate was $0.1 \mathrm{~mL} \mathrm{~min}^{-1}$ ). Dilution corrected counts per second were ${ }^{115}$ In normalized to correct for instrumental drift over the course of an experiment. A high concentration standard in $1 \% \mathrm{HNO}_{3}$ was diluted in known time-resolved proportions with the standard matrix (1\% $\mathrm{HNO}_{3}$ ) for calibration. The range of concentrations measured in this study was $0.6 \times 10^{-6}$ moles $L^{-1}$ to $3.5 \times 10^{-6}$ moles $L^{-1}$ for $\mathrm{Mg}$ and $0.3 \times 10^{-6}$ moles $L^{-1}$ to $1.8 \times 10^{-6}$ moles $L^{-1}$ for Si. Relative error on concentrations (95\% confidence interval) ranged from $2.6 \%$ to $4.6 \%$ for $\mathrm{Mg}$ and from $4.9 \%$ to $14.4 \%$ for $\mathrm{Si}$, from high to low concentration. The lower precision for Si measurements is attributed to higher blanks resulting from the use of a glass spray-chamber with the ICP-MS. Blank filters were run using identical eluents as used in sample runs. Blank corrections were $0.014 \pm 0.002 \times 10^{-6}$ moles $\mathrm{L}^{-1}$ for $\mathrm{Mg}$ and $0.19 \pm 0.02 \times 10^{-6}$ moles $\mathrm{L}^{-1}$ for Si. Although high, the Si blank was very stable, allowing measurements of blank-corrected Si concentrations as low as $0.2 \times 10^{-6}$ moles $\mathrm{L}^{-1}$. Although the glass spray chamber is not prohibitive, in future studies it will be preferable to replace it with a Teflon spray chamber. As blank-corrected concentrations were measured every $1.8 \mathrm{~s}$ and the eluent residence time was $2.1 \mathrm{~s}$, effluent concentration data was smoothed using a 5-point running average to reflect the renewal time of the eluent in the reactor.

\subsection{Flow-through dissolution experiment design}

Several experiments were conducted to explore the potential applications of the FT-TRA experimental set up.

\subsubsection{Dissolution rate parameters}

To provide a comparison with previous studies, a dissolution experiment was specifically designed to calculate the dissolution rate parameters of forsterite $\left(k_{\mathrm{H}}^{+}\right.$and $n$ ). For that purpose, dissolution rates must be measured at steady-state and under surface-controlled conditions. To establish whether the latter condition is met in our experimental design, a series of dissolution experiments was carried out using a forsterite subsample (sample 1, Table 1), which was exposed to a nitric acid solution at $\mathrm{pH} 2.3$ under different flow rates ranging from 0.01 to $0.7 \mathrm{~mL} \mathrm{~min}^{-1}$, and maintained until steady-state [Mg, Si] concentrations were reached.

Once surface-controlled conditions were confirmed, another forsterite subsample (sample 2: BET surface area of $3.39 \times 10^{-2} \mathrm{~m}^{2} \mathrm{~g}^{-1}$; Table 1 ) was subjected to eluents with $\mathrm{pH}$ decreasing stepwise (5.6, 4.0, 3.5, 3.0, 2.3 ), and the durations of the $\mathrm{pH}$ plateaus were maintained until the on-line ICP-MS measurements indicated steady-state Mg and Si concentrations. The dissolution experiment on sample 2 lasted approximately 234 min to cover all 5 pH steps. Because steady-state dissolution could not be achieved at $\mathrm{pH}$ 5.6, another experiment was conducted by exposing a third forsterite subsample (sample 3; Table 1) to deionized water (DIW) only for a longer period of time (224 min).

\subsubsection{Dissolution under transient conditions and replication}

Replicate analyses were conducted with five subsamples from the same forsterite sample. In each of the five experiments, a sample was weighed (samples 4-8, Table 1 ) and subjected first to a continuous flow of distilled, de-ionized water (DIW; $\mathrm{pH}=5.6$ ) for $\sim 1950 \mathrm{~s}$ (32.5 min). Eluent acidity was then gradually ramped up by mixing $\mathrm{HNO}_{3}(1 \%)$ to decrease eluent $\mathrm{pH}$ to 3.3 , which was maintained for $1200 \mathrm{~s}$ (20 min). Afterwards, eluent acidity was ramped up further to decrease eluent $\mathrm{pH}$ to 2.3 , which was maintained for $\sim 1400 \mathrm{~s}$ ( $23 \mathrm{~min}$ ) before raising the eluent $\mathrm{pH}$ back to $\mathrm{pH}=5.6$ (DIW). Effluent $\mathrm{Mg}$ and Si concentrations were continuously measured, providing dissolution rate data over a range of $\mathrm{pH}$ (5.6 to 2.3) in less than $9000 \mathrm{~s}$ (150 $\mathrm{min}$ ). The goals of this experiment are to assess reproducibility between subsamples and to document transient dissolution patterns.

\subsection{Calculation of surface normalized dissolution rates and dissolution rate parameters $\left(k_{H^{+}}, n_{H^{+}}\right)$}

Surface area normalized forsterite dissolution rates (moles $\mathrm{m}^{-2} \mathrm{~s}^{-1}$ ) as a function of $\mathrm{pH}$ are calculated by multiplying the time resolved concentrations (moles $\mathrm{L}^{-1}$ ) of $\mathrm{Mg}$ or $\mathrm{Si}$ by the eluent flow rate

Table 1

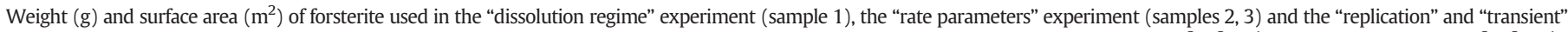

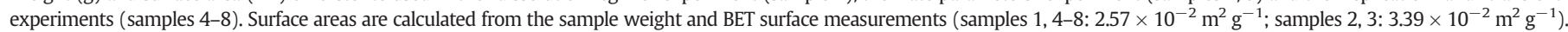
Sample loss is estimated by integrating the total moles of $\mathrm{Mg}$ released during each experiment.

\begin{tabular}{|c|c|c|c|c|}
\hline Sample & Experimental pH & Sample weight $g$ & $\mathrm{~A}\left(\times 10^{-4} \mathrm{~m}^{2}\right)$ & Experimental sample loss \% \\
\hline 1 & 2.3 (constant) & $8.17 \times 10^{-3}$ & 2.10 & 0.30 \\
\hline 2 & 5.6-4.0-3.5-3.0-2.3 (step-wise decrease) & $20.24 \times 10^{-3}$ & 6.88 & 0.28 \\
\hline 3 & 5.6 (constant) & $22.01 \times 10^{-3}$ & 7.48 & 0.20 \\
\hline 4 & 2.3-5.6 (transient/constant) & $17.78 \times 10^{-3}$ & 4.58 & 0.32 \\
\hline 5 & $2.3-5.6$ (transient/constant) & $13.58 \times 10^{-3}$ & 3.49 & 0.33 \\
\hline 6 & 2.3-5.6 (transient/constant) & $12.85 \times 10^{-3}$ & 3.31 & 0.21 \\
\hline 7 & 2.3-5.6 (transient/constant) & $20.27 \times 10^{-3}$ & 5.21 & 0.22 \\
\hline 8 & $2.3-5.6$ (transient/constant) & $17.78 \times 10^{-3}$ & 4.58 & 0.26 \\
\hline
\end{tabular}


( $\left.Q ; \mathrm{L} \mathrm{s}^{-1}\right)$ and dividing by the sample surface area $\left(A . ; \mathrm{m}^{2}\right)$, taking into account the stoichiometry of the forsterite used in the experiment $\left(\mathrm{Mg}_{1.81} \mathrm{Fe}_{0 \cdot 18} \mathrm{Ni}_{0.01} \mathrm{SiO}_{4} ;\right.$ Fo91):

Surface normalized dissolution rates (moles forsterite $\mathrm{m}^{-2} \mathrm{~s}^{-1}$ ) $=$

$$
\begin{aligned}
& \left([\mathrm{Mg}] / 1.81\left(\text { moles L }^{-1}\right) \times Q\left(\mathrm{~L} \mathrm{~s}^{-1}\right)\right) / \mathrm{A}\left(\mathrm{m}^{2}\right) \\
& \left([\mathrm{Si}]\left(\text { moles L }^{-1}\right) \times Q\left(\mathrm{~L} \mathrm{~s}^{-1}\right)\right) / \mathrm{A}\left(\mathrm{m}^{2}\right) .
\end{aligned}
$$

To describe forsterite dissolution in our experimental set up, Eq. (1) can be simplified. It has been previously determined that forsterite dissolution between $\mathrm{pH} 1$ and 6 only depends on the activity of $\mathrm{H}^{+}\left(\mathrm{N}_{\mathrm{p}}=\right.$ 1 ). In addition, since only a very small fraction of the sample is dissolved during the experiments (Table 1 ), $m / m_{0} \approx 1$. Thus, Eq. ( 1 ) can be simplified to:

$R_{f}\left(\right.$ moles s $\left.^{-1}\right)=A \times k_{H^{+}} \times a_{H^{+}}^{n}$

which results in a simple linear relationship between the logarithm of the surface normalized forsterite dissolution rate $\left(r=R_{f} / A\right)$ and $\mathrm{pH}$ :

$\log (r)=\log k_{H^{+}}-n p H$.

\section{Results and discussion}

\subsection{Determination of forsterite dissolution rate parameters}

\subsubsection{Forsterite dissolution regime}

Dissolution under surface-controlled conditions, as opposed to transport-controlled conditions, is a pre-requisite to obtain dissolution rate constants that are intrinsic to the mineral studied and independent of experimental conditions during measurement (e.g. Colombani, 2008 and references therein). Sample 1 (Table 1) was dedicated to evaluating the dissolution regime of forsterite in our experimental set up at $\mathrm{pH}$ 2.3. Steady state [Mg, Si] concentrations reached at constant eluent $\mathrm{pH}$ of 2.3 but at different flow rates increase linearly with the residence time of eluent in the reactor, indicating that the forsterite dissolution rate is constant and independent of flow rate (Mg: Fig. 3A; Si: Fig. 3B). This is taken as an indication that dissolution in our experimental set up at $\mathrm{pH} 2.3$ is surface-controlled, i.e. the rate of detachment of dissolving species from the mineral surface is slower than the rate at which dissolved products diffuse to the bulk solution, and the rate of diffusion of $\mathrm{H}^{+}$from the bulk solution to the mineral surface is faster than the rate of consumption of protons by the surface reaction. A telltale sign of transport control would be a decrease in dissolution rates with decreasing flow rate, indicating that transport through the widening boundary layer at the interface between solution and grain surface limits, or at least contributes to limiting the dissolution rate (transport or mixed controlled regimes). We thus conclude that forsterite dissolution is surface-controlled at $\mathrm{pH}$ 2.3. A more complete investigation of dissolution regime using FTTRA is presented in a companion paper (De Baere et al., submitted for publication).

\subsubsection{Forsterite dissolution under acidic conditions}

To validate our proposed methodology for the determination of dissolution rate parameters, the time-resolved $[\mathrm{Mg}, \mathrm{Si}]$ concentrations and $\mathrm{Mg} / \mathrm{Si}$ molar ratios measured during the dissolution of sample 2 (Fig. 4A) were used for comparison with previous studies. $\mathrm{Mg}$ and $\mathrm{Si}$ concentrations are initially high and decreased sharply during the first dissolution step in DIW at pH 5.6 without reaching steady-state after nearly 90 min of dissolution. Such a dissolution pattern (parabolic kinetics) is attributed to the faster dissolution of high surface free energy sites that have been produced during sample preparation (Chou and Wollast, 1984). Subsequently, Mg and Si concentrations increase sharply at each
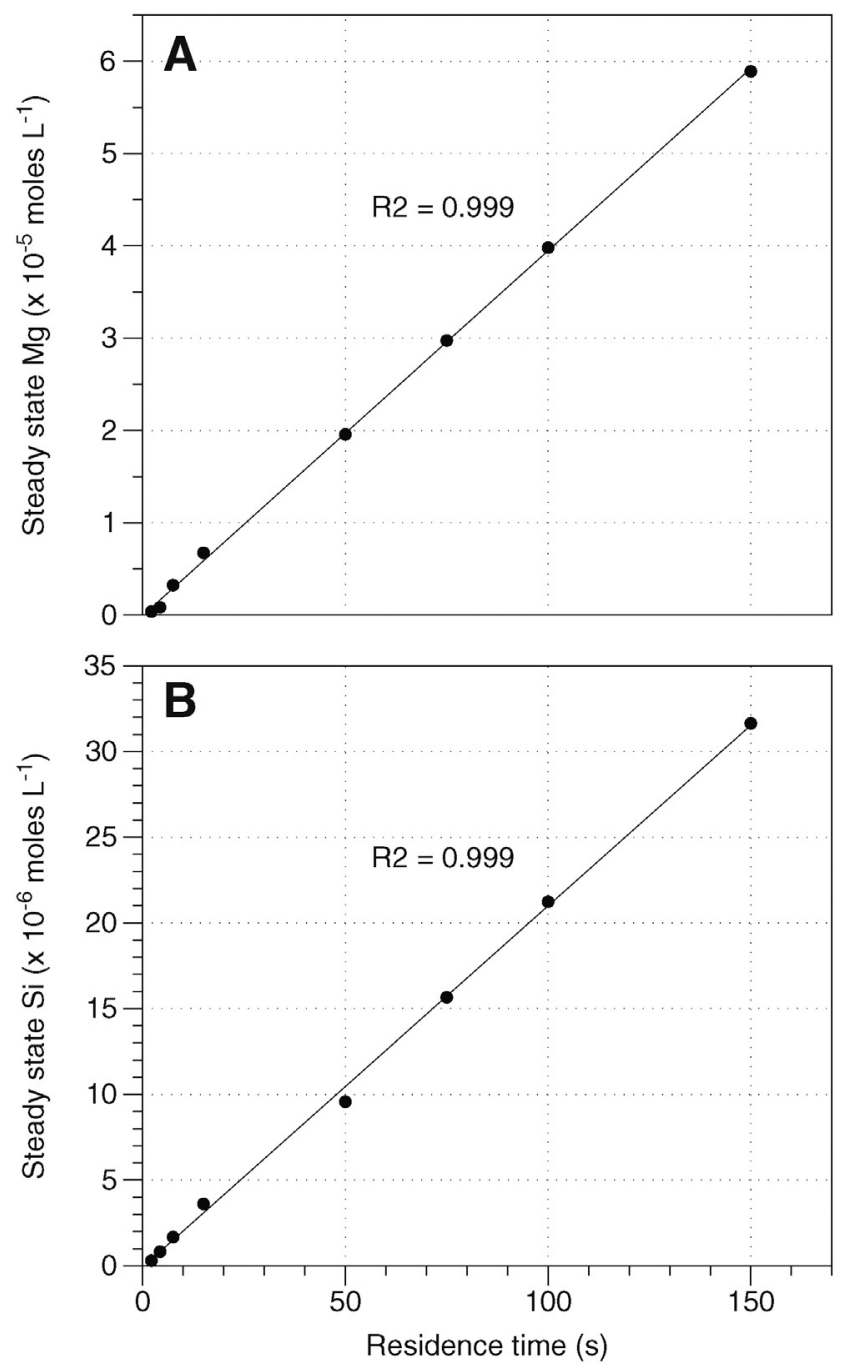

Fig. 3. Average steady state $\mathrm{Mg}(\mathrm{A})$ and $\mathrm{Si}$ (B) concentrations (sample 1) versus eluent residence time (calculated by dividing flow cell volume $(25 \mu \mathrm{L})$ by varying eluent flow rates).

step when pH decreases, and continue to increase more gradually thereafter, suggesting a gradual increase in active surface area (consistent with the increase in surface area when forsterite is immersed in acidic solutions for $24 \mathrm{~h}$; Pokrovsky and Schott, 2000b). Concentrations eventually plateau at each $\mathrm{pH}$ step.

To calculate dissolution rate parameters, we used the on-line ICPMS data to monitor the time needed to reach or approach steady-state dissolution before changing the $\mathrm{pH}$ of the eluent. Time segments with constant $\mathrm{Mg}$ and $\mathrm{Si}$ concentrations were then selected on each plateau (Fig. 4A) and averaged to quantify $k_{\mathrm{H}^{+}}$and $n_{\mathrm{H}^{+}}$by weighted linear regression (Fig. 4B), following Eq. (4). Weights were allocated according to the number of data points collected at constant $\mathrm{Mg}$ and Si concentrations. Since steady state dissolution could not be reached in DIW, only data obtained at pHs 4.0, 3.5, 3.0 and 2.3 were considered.

Dissolution rate parameters obtained in this experiment are in reasonable agreement with previous studies, and fit best with the results from Pokrovsky and Schott (2000a) (Table 2; Fig. 5). The dissolution rate measured at $\mathrm{pH} 4.0$ deviates slightly from the linear trend, particularly when calculating forsterite dissolution rates from $\mathrm{Mg}$ release rates (Fig. 4B). This may indicate that at this $\mathrm{pH}$, although $\mathrm{Mg}$ concentrations appeared to have reached a plateau (Fig. 4A), these concentrations may still have been decreasing very slowly. This is further supported by the relatively high $\mathrm{Mg} / \mathrm{Si}$ also obtained at $\mathrm{pH} 4.0(2.13 \pm 0.16)$ compared to forsterite stoichiometry $(1.81 \pm 0.07)$, indicating that the Si-rich surface leached layer was still deepening. Si-based dissolution rates deviate 

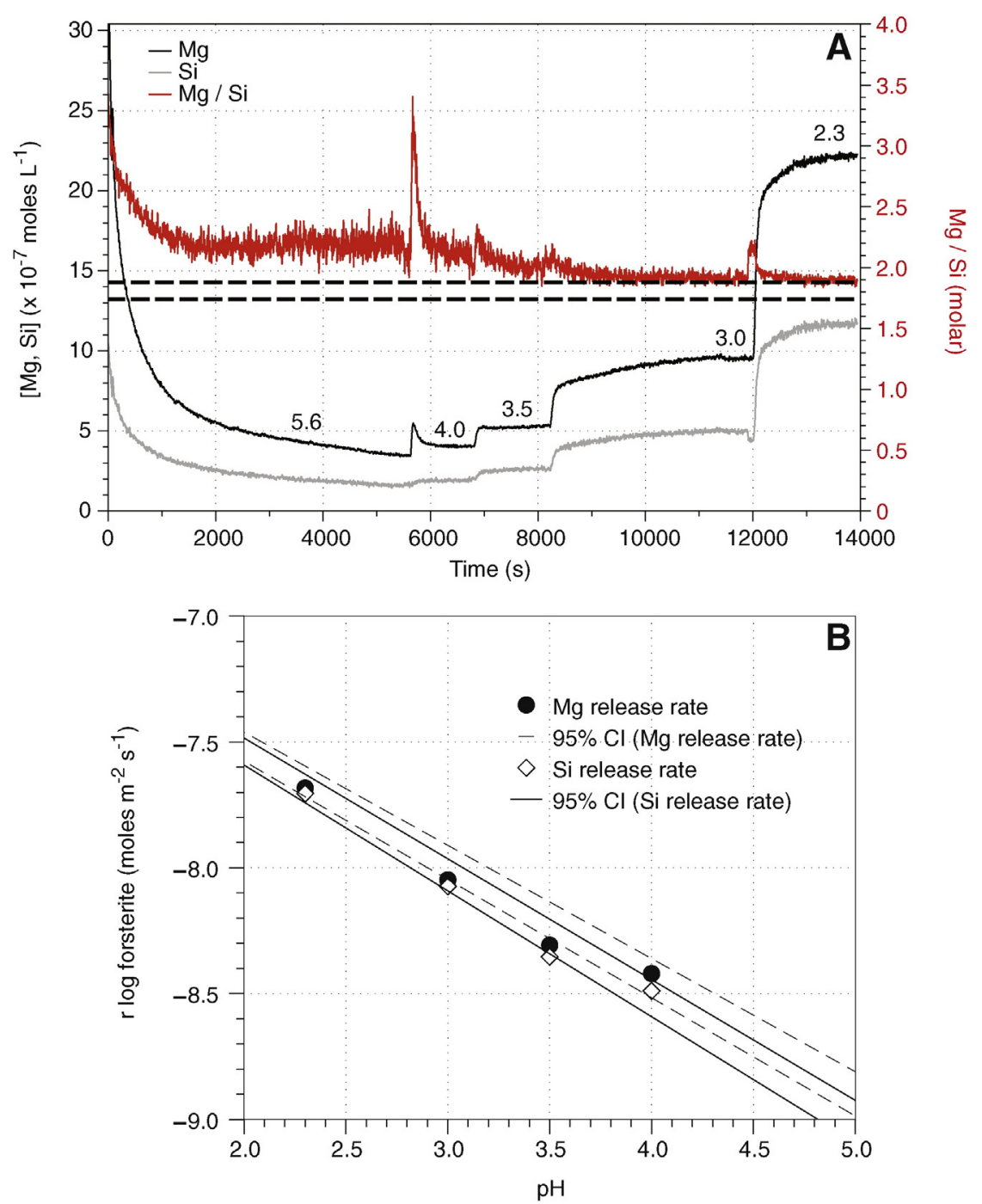

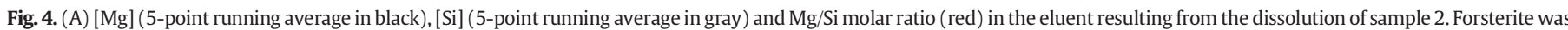

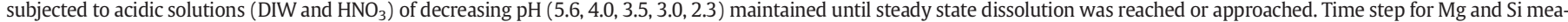

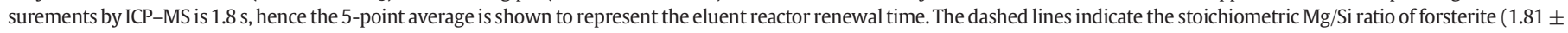

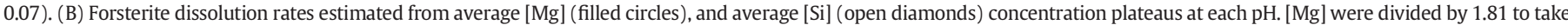

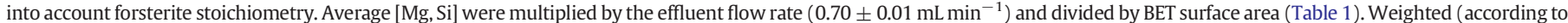

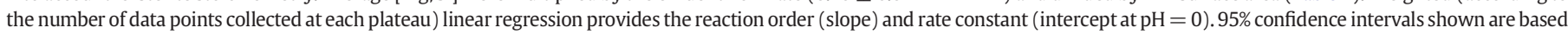
on the weighted linear regression. (For interpretation of the references to color in this figure legend, the reader is referred to the web version of this article.)

Table 2

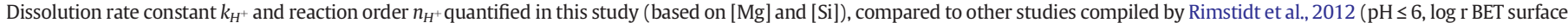
area normalized $\mathrm{Mg}$, Si data).

\begin{tabular}{|c|c|c|c|c|}
\hline \multirow[t]{2}{*}{ Study } & Rate constant $k_{H^{+}}\left(\times 10^{-7}\right.$ moles $\left.\mathrm{m}^{-2} \mathrm{~s}^{-1}\right)$ & Reaction order $n_{H^{+}}$ & Rate constant $k_{H^{+}}\left(\times 10^{-7}\right.$ moles $\left.\mathrm{m}^{-2} \mathrm{~s}^{-1}\right)$ & Reaction order $n_{H^{+}}$ \\
\hline & \multicolumn{2}{|l|}{ Based on $[\mathrm{Mg}]$} & \multicolumn{2}{|l|}{ Based on [Si] } \\
\hline This study (sample 2) & $2.15-2.48^{(a)}$ & $0.46 \pm 0.01^{(\mathrm{b})}$ & $2.40-2.73^{(a)}$ & $0.49 \pm 0.01^{(b)}$ \\
\hline Blum and Lasaga (1988) & & & $0.52-1.78^{(\mathrm{c})}$ & $0.50 \pm 0.08^{(\mathrm{d})}$ \\
\hline Wogelius and Walther (1991) & $0.19-5.09^{(\mathrm{c})}$ & $0.53 \pm 0.16^{(\mathrm{d})}$ & $0.26-2.43^{(\mathrm{c})}$ & $0.53 \pm 0.12^{(\mathrm{d})}$ \\
\hline Pokrovsky and Schott (2000a) & $1.28-2.90^{(\mathrm{c})}$ & $0.51 \pm 0.04^{(\mathrm{d})}$ & $1.97-3.91^{(\mathrm{c})}$ & $0.53 \pm 0.04^{(\mathrm{d})}$ \\
\hline Rosso and Rimstidt (2000) & $0.93-1.22^{(\mathrm{c})}$ & $0.50 \pm 0.02^{(\mathrm{d})}$ & $0.78-1.03^{(\mathrm{c})}$ & $0.44 \pm 0.02^{(\mathrm{d})}$ \\
\hline Olsen (2007) & & & $0.70-3.11^{(\mathrm{c})}$ & $0.53 \pm 0.10^{(\mathrm{d})}$ \\
\hline Olsen and Rimstidt (2008) & $0.46-1.39^{(\mathrm{c})}$ & $0.44 \pm 0.09^{(\mathrm{d})}$ & $0.86-1.39^{(\mathrm{c})}$ & $0.48 \pm 0.04^{(\mathrm{d})}$ \\
\hline Luce et al. (1972) & $8.29-42.92^{(\mathrm{c})}$ & $0.32 \pm 0.10^{(\mathrm{d})}$ & $8.94-102.05^{(\mathrm{c})}$ & $0.64 \pm 0.45^{(\mathrm{d})}$ \\
\hline Grandstaff (1986) & $0.13-60.97^{(\mathrm{c})}$ & $1.09 \pm 0.35^{(\mathrm{d})}$ & $0.12-64.36^{(\mathrm{c})}$ & $1.10 \pm 0.35^{(\mathrm{d})}$ \\
\hline Golubev et al. (2005) & $0.12-0.34^{(\mathrm{c})}$ & $0.16 \pm 0.06^{(\mathrm{d})}$ & $0.16-0.41^{(\mathrm{c})}$ & $0.19 \pm 0.05^{(\mathrm{d})}$ \\
\hline
\end{tabular}

a Range associated with $95 \%$ confidence interval $(2 \sigma)$ of weighted linear regression intercept. Weighted linear regression is based on number of data points associated with each [Mg, Si] steady state plateau $\left(\mathrm{n}_{\mathrm{pH}=4.0}=241 ; \mathrm{n}_{\mathrm{pH}=35}=451 ; \mathrm{n}_{\mathrm{pH}=30}=644 ; \mathrm{n}_{\mathrm{pH}=23}=491\right)$.

b Error $=95 \%$ confidence interval $(2 \sigma)$ associated with weighted linear regression slope.

c Range associated with $95 \%$ confidence interval $(2 \sigma)$ of linear regression intercept.

${ }^{\mathrm{d}}$ Error $=95 \%$ confidence interval $(2 \sigma)$ associated with linear regression slope. 

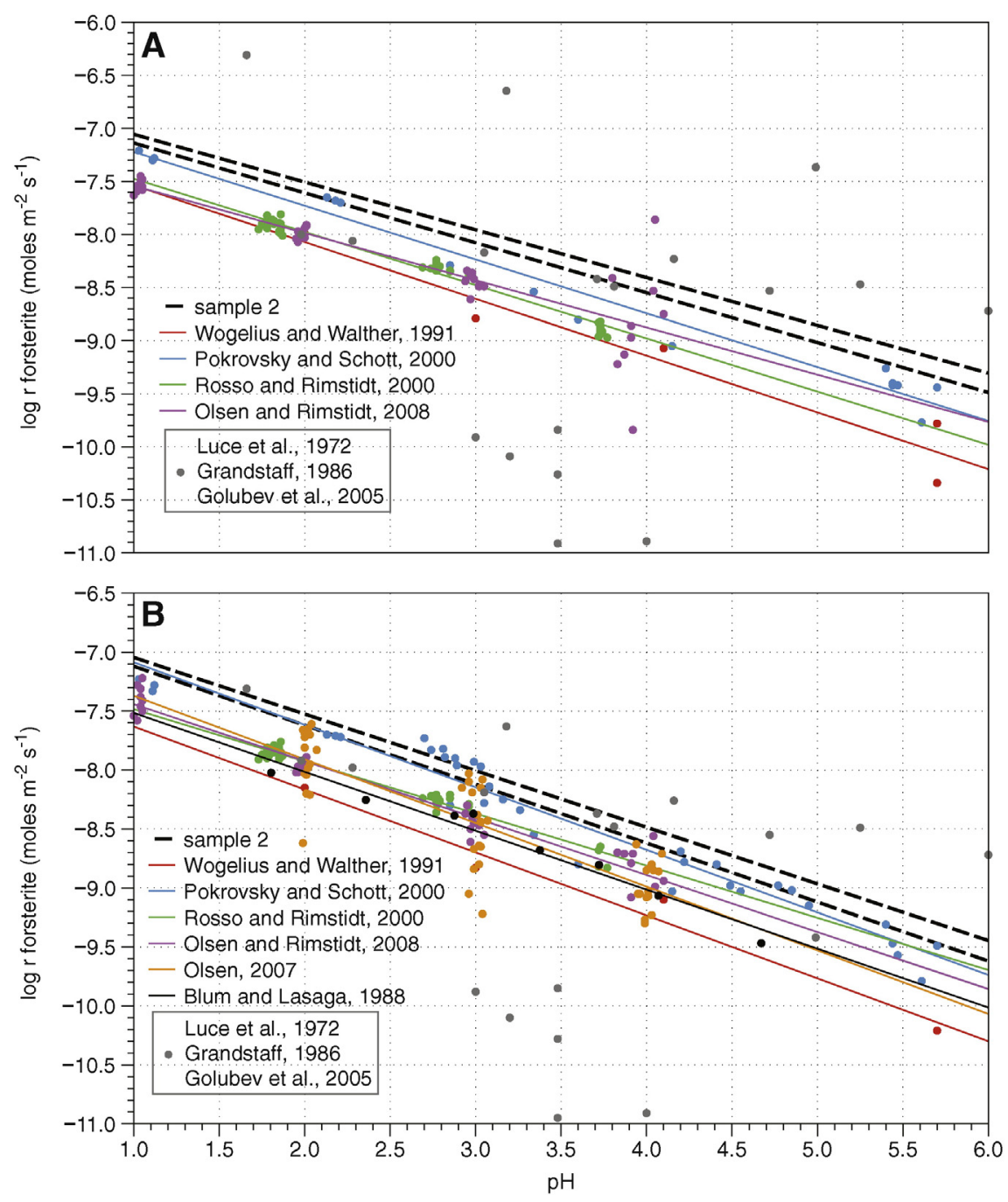

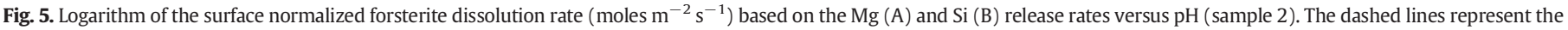

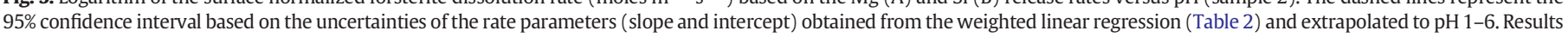

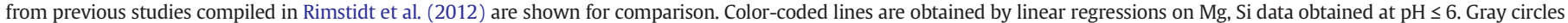

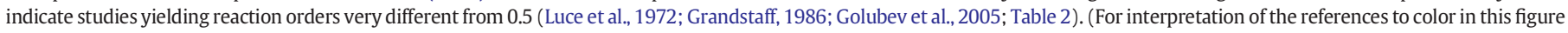
legend, the reader is referred to the web version of this article.)

less (Fig. 4B), suggesting that under acidic conditions and when $\mathrm{pH}$ is decreasing Si release rates reach or approach steady state faster than $\mathrm{Mg}$ release rates. Nonetheless, these results confirm the suitability of FTTRA and on-line ICP-MS to generate meaningful dissolution rate data relatively quickly (approximately $4 \mathrm{~h}$ ( $240 \mathrm{~min}$ ) for $4 \mathrm{pH}$ steps and including the initial DIW step), which would allow, at least for minerals reaching steady state dissolution rapidly, replicate analyses, dissolution process studies, and the generation of a database suitable for statistical analysis.

\subsubsection{Forsterite dissolution in DIW ( $\mathrm{pH}$ 5.6)}

Because steady state concentrations could not be reached at $\mathrm{pH}=5.6$ after $\sim 90 \mathrm{~min}$, an additional dissolution experiment with DIW only was conducted for 224 min (sample 3, Fig. 6). Even with this extended period of exposure, $\mathrm{Mg}$ and $\mathrm{Si}$ release rates at the end of this experiment were still decreasing, although $\mathrm{Mg} / \mathrm{Si}$ reached forsterite stoichiometry, indicating congruent dissolution, after approximately $6000 \mathrm{~s}$ (100 min). Unlike the gradual increase in dissolution rates occurring when $\mathrm{pH}$ decreases (Fig. 4A), which could be attributed to a gradual increase in surfaceactive area with the gradual deepening of the Si-rich surface layer, the gradual decrease in the dissolution rate observed in DIW may be, instead, an indication of gradual surface passivation once stoichiometric dissolution is achieved and the depth of the Si-rich surface layer has stabilized.
This could be a result of the gradual polymerization of silica tetrahedra in the leached layer (Pokrovsky and Schott, 2000a). Once the silica-rich layer depth has reached steady-state, the rate limiting step for forsterite dissolution is the release of silica from the surface altered layer (Liu et al., 2006), accounting for the gradual decrease in Mg concentration. Notwithstanding stoichiometric dissolution, the rates of $\mathrm{Mg}$ and Si release at the end of this experiment are still significantly higher $(\log r=-8.5)$ than predicted with the dissolution rate parameters derived at lower $\mathrm{pH}$ (Fig. 4B) and in previous studies (Fig. 5). This observation indicates that it takes more than $224 \mathrm{~min}$ to reach steady state dissolution of forsterite at $\mathrm{pH}$ 5.6. It is well established that reaching steady state dissolution of forsterite at higher $\mathrm{pH}$ takes much longer than under more acidic conditions (Pokrovsky and Schott, 2000a). This may be because of slow surface passivation, or because forsterite dissolution is not surface-controlled at this pH (Rimstidt, 2015). In fact, Rimstidt et al. (2012) document a change in dissolution reaction mechanism going from low to high pH at $25^{\circ} \mathrm{C}$ and split their dataset at pH 5.6. Regardless of the mechanism responsible, for forsterite dissolution, the use of FT-TRA and on-line ICP-MS measurements, as applied in this experiment, may be limited to lower $\mathrm{pH}$ conditions (Section 4.1.2). Indeed, if the time needed to reach steady state dissolution exceeds $12 \mathrm{~h}$ ( $720 \mathrm{~min}$ ), it may be too costly to study mineral dissolution with our set-up by direct on-line ICP-MS analysis. 


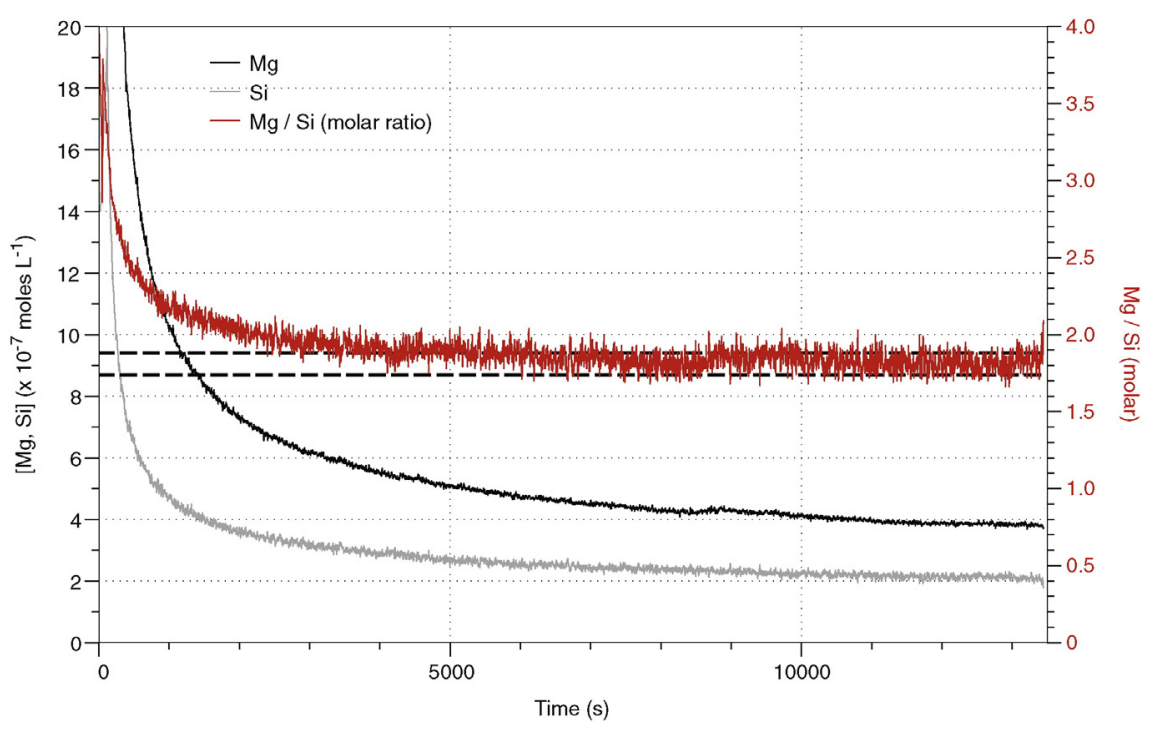

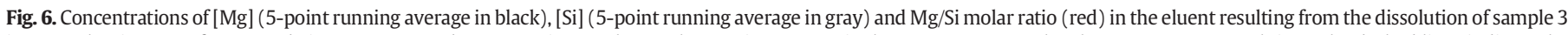

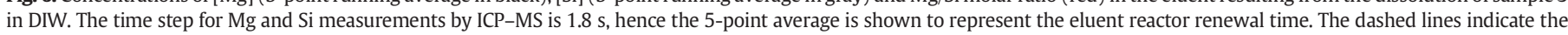
stoichiometric $\mathrm{Mg} / \mathrm{Si}$ ratio of forsterite $(1.81 \pm 0.07)$. (For interpretation of the references to color in this figure legend, the reader is referred to the web version of this article.)

\subsubsection{General applicability of FT-TRA to estimate mineral dissolution parameters}

The last conclusion in the previous section raises questions about the broader applicability of the proposed approach. One of the main advantages of FT-TRA over conventional flow-through reactors for measuring mineral dissolution parameters is the shorter time required to reach steady-state concentrations of dissolved products. In our experiment, quasi steady-state concentrations are reached in less than one hour at $\mathrm{pH} \leq 4$ (Fig. 4A), while it took 8 to $75 \mathrm{~h}$ ( 480 to $4500 \mathrm{~min}$ ) during the extensive forsterite dissolution experiments conducted by Pokrovsky and Schott (2000a) under similar pH conditions, but using a conventional mixed flow reactor. The main differences between the two experimental designs are the larger surface area to volume ratio $(\mathrm{A} / \mathrm{V})$ and the much smaller volume of the reactor in our set up ( $25 \mu \mathrm{L}$ vs $250 \mathrm{~mL}$ ). While there are no a priori reasons to expect that higher A/V would decrease the time needed to reach steady state concentrations, the much smaller volume of the reactor is an important characteristic which can largely explain this observation. The time necessary to reach steadystate concentrations in a flow reactor depends on both the times it takes for the mineral surface to reach steady dissolution $\left(\mathrm{T}_{\text {diss }}\right)$, and the time it takes to renew the solution within the reactor $\left(\mathrm{T}_{\text {flush }}\right)$. With their comparatively large volumes, when mixed flow reactors are used to measure dissolution rates of forsterite or other minerals reaching steady state dissolution relatively quickly, $\mathrm{T}_{\text {flush }}>>\mathrm{T}_{\text {diss }}$ and the time needed for the dissolution experiment to reach steady-state concentrations is largely dictated by the residence time of the eluent in the reactor (e.g. 6-50 h (360-3000 min) in the $\mathrm{pH}<4$ experiments conducted by Pokrovsky and Schott, 2000a). The eluent residence time in our flowthrough cell is only $2.1 \mathrm{~s}$ (i.e. $\mathrm{T}_{\text {flush }}<<\mathrm{T}_{\text {diss }}$ ); therefore the time needed for dissolution experiments to reach steady-state concentrations is entirely dictated by the properties of the mineral surface.

The time advantage of FT-TRA is clearly apparent in our study because forsterite reaches steady-state dissolution rapidly, at least at $\mathrm{pH} \leq 4$. If other minerals or conditions (e.g. forsterite dissolution in DIW) require longer time periods (more than $720 \mathrm{~min}$ ) to reach steady-state dissolution, on-line ICP-MS analysis may become prohibitively expensive. In this case, we suggest two possible alternatives: (1) pre-conditioning the mineral off line prior to on-line ICP-MS effluent measurement or (2) collection of time-series samples over a much longer period using an automated fraction collector, followed by off-line ICP-MS analysis. The choice between these two alternative approaches would depend on the goal of the experiment, and both approaches could be combined. If the goal is to determine dissolution rate parameters, fraction collection would be particularly suited, since the experiment could be continued over much longer periods of time with minimal attendance. The advantage of high analytical time resolution would be lost but this is of no consequence for this particular application. Of course, for minerals with $\mathrm{T}_{\text {diss }} \gg \mathrm{T}_{\text {flush }}$, mixed flow reactors may be equally suited to measure dissolution rate parameters, but the automation of our set-up would still facilitate this task. On the other hand, if the goal of the experiment is to study rapidly evolving transient dissolution events, the high time resolution afforded by the present approach is needed, and neither FT-TRA with fraction collector nor conventional mixed flow reactor could be used effectively. In this case, FT-TRA and on-line ICP-MS would be the tool of choice to document transient dissolution of minerals or minerals having been subjected to various pre-treatments. For instance, off-line preconditioning of minerals under varying conditions prior to on-line ICP-MS measurements could prove particularly useful to study the factors controlling surface passivation or exfoliation, two important processes which regulate weathering and carbonation of minerals (e.g. Olsson et al., 2012).

\subsection{Replicate analyses and dissolution under transient conditions}

\subsubsection{Reproducibility of forsterite dissolution under identical conditions}

The shorter experimental durations afforded by our small volume flow-through cell facilitate replicate experiments to assess the inherent variability of forsterite dissolution between closely related subsamples. Results obtained with one of the five replicate subsamples (sample 6) subjected to the same dissolution sequence are illustrated in Fig. $7 \mathrm{~A}$ (results from the other replicates are reported in the supplementary material). $\mathrm{Mg}$ and Si concentrations follow a similar pattern as in the previous experiment. They start high and sharply decrease in DIW, increase as incoming effluent $\mathrm{pH}$ decreases and drop when $\mathrm{pH}$ increases. $\mathrm{pH}$ changes associated with forsterite dissolution calculated from the concentration of $\mathrm{Mg}^{2+}$ in the effluent are $<0.004 \mathrm{pH}$ units and therefore negligible. The $\mathrm{pH}$ values reported in our experiments (Fig. 7B) are thus the $\mathrm{pH}$ of the incoming solutions.

Multiplying the time-resolved concentrations obtained with the five replicates by the effluent flow rate, which was identical for the five experiments, and dividing by the surface area of each subsample (Table 1) reveal a near 2-fold variability in the surface normalized rate of dissolution of the replicates (Fig. 8). In addition, not only are the surfacenormalized dissolution rates generated during the 5 experiments 

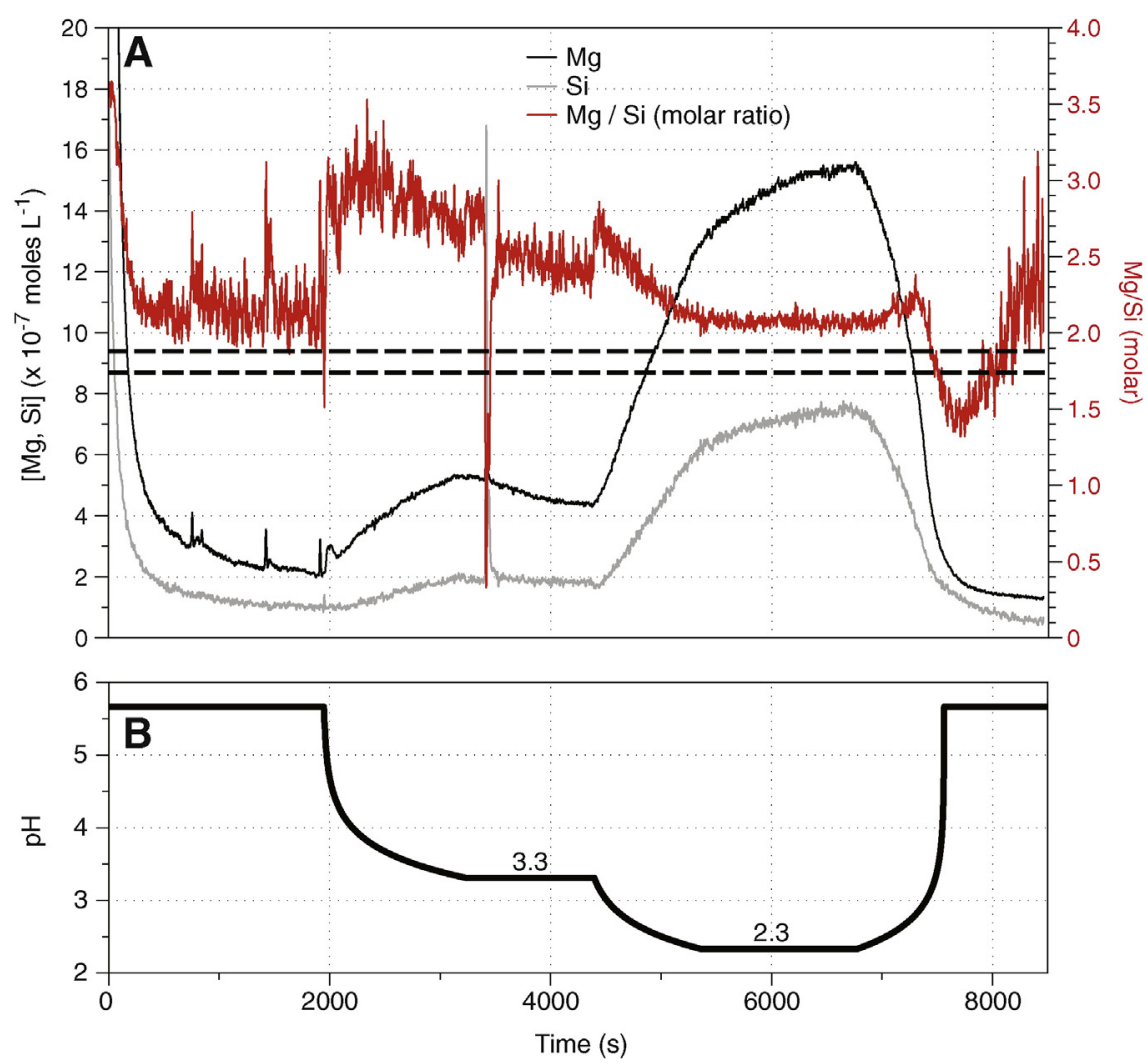

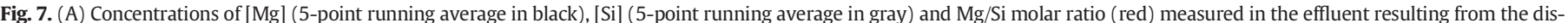

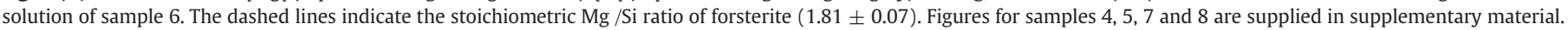

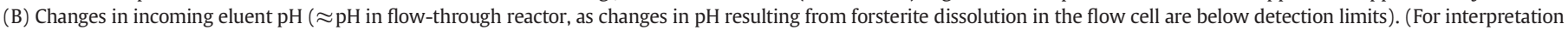
of the references to color in this figure legend, the reader is referred to the web version of this article.)

different, but the rate at which steady-state dissolution is approached also varies between subsamples. Differences in surface-normalized dissolution rates between subsamples may reflect variations in reactive surface area, while the gradual increase in dissolution rate at constant $\mathrm{pH}$ of 2.3 and/or $\mathrm{pH}$ of 3.3 may reflect a gradual increase in reactive surface area with time in 4 of the 5 subsamples. The variability observed in this experiment is surprising considering that the subsamples were treated and dissolved under the same conditions, and further points to the importance of replicating dissolution experiments (Rosso and Rimstidt, 2000) and the continuing need to fully understand the underlying reasons for this variability.

\subsubsection{Forsterite dissolution stoichiometry under transient eluent conditions}

FT-TRA analysis reveals that the stoichiometry of forsterite dissolution displays a striking variability associated with eluent $\mathrm{pH}$ changes (Figs. 4A; 7A). Mg/Si molar ratio of the eluent is initially much higher and gradually decreases towards the stoichiometric ratio of the forsterite sample $(1.81 \pm 0.07)$. When the $\mathrm{pH}$ of the eluent gradually decreases, $\mathrm{Mg} / \mathrm{Si}$ often increases sharply and relaxes back towards the forsterite stoichiometric ratio. In contrast, when the $\mathrm{pH}$ of the eluent increases (at $\mathrm{t}=7500 \mathrm{~s}$ (125 min); Fig. 7A; supplementary material), invariably, $\mathrm{Mg} / \mathrm{Si}$ drops below the stoichiometric ratio and gradually rises thereafter. In addition, the time resolved concentrations generated at $\mathrm{pH} 3.3$ with sample 6 (Fig. 7A) document a large and sudden change in Si concentrations, which is clearly reflected in the $\mathrm{Mg} / \mathrm{Si}$ time series data. Likewise, smaller but significant and rapid changes in Mg concentration are observed during the first dissolution step in DIW. These peaks indicate that mineral dissolution is not necessarily a continuous process, but may be punctuated by abrupt events, which require the temporal resolution afforded by our approach to be documented.
4.2.2.1. Monitoring the surface leached layer thickness during transient eluent conditions. The preferential release of $\mathrm{Mg}$ during the early stage of forsterite dissolution at low $\mathrm{pH}$ has been widely reported (e.g. Luce et al., 1972; Wogelius and Walther, 1991; Pokrovsky and Schott, 2000a; Rosso and Rimstidt, 2000), and attributed to the formation of a Si-rich leached layer due to exchange reaction between $\mathrm{Mg}^{2+}$ and $\mathrm{H}^{+}$ (e.g. Pokrovsky and Schott, 2000a). Higher Mg/Si ratios of the dissolved products, compared to the $\mathrm{Mg} / \mathrm{Si}$ ratio of the dissolving forsterite, indicate preferential release of $\mathrm{Mg}$ and deepening of the Si-rich surface layer. Quantum mechanical simulations by Liu et al. (2006) suggest that under acidic conditions, oxygen atoms at a specific lattice position ( $\mu 3-0)$ become protonated, which lengthens and weakens the bonds holding Mg. The rate of release of $\mathrm{Mg}$ by this reaction is faster at kinks or edges. This mechanism could account for the observed high $\mathrm{Mg} / \mathrm{Si}$ released when forsterite is first exposed to more acidic solutions. On the other hand, eluent ratios lower than forsterite stoichiometry indicate preferential dissolution of $\mathrm{Si}$ and partial erosion of the Si-rich layer.

Changes in the mean thickness of the Si-rich leached surface layer as dissolution proceeds are calculated following Chou and Wollast (1984):

$$
\begin{aligned}
& \Sigma \mathrm{Mg}_{(t)}=\Sigma[\mathrm{Mg}]_{i} \times Q \times \Delta t \\
& \Sigma \mathrm{Si}_{(t)}=\Sigma[\mathrm{Si}]_{i} \times Q \times \Delta t
\end{aligned}
$$

where $\Sigma \mathrm{Mg}_{(t)}$ and $\Sigma \mathrm{Si}_{(t)}$ are the moles of $\mathrm{Mg}$ and Si dissolved since the beginning of the experiment to time $t,[\mathrm{Mg}]_{i}$ and $[\mathrm{Si}]_{i}$ are the concentrations (moles $\mathrm{L}^{-1}$ ) measured at time $i, \Delta t$ is the time step of ICP-MS analysis $(1.8 \mathrm{~s})$ and $Q$ is the effluent flow rate $\left(\mathrm{L} \mathrm{s}^{-1}\right)$

$V_{\mathrm{Mg}(t)}=1.81 \times \Sigma \mathrm{Mg}_{(t)} \times M V_{\text {forsterite }}$ 

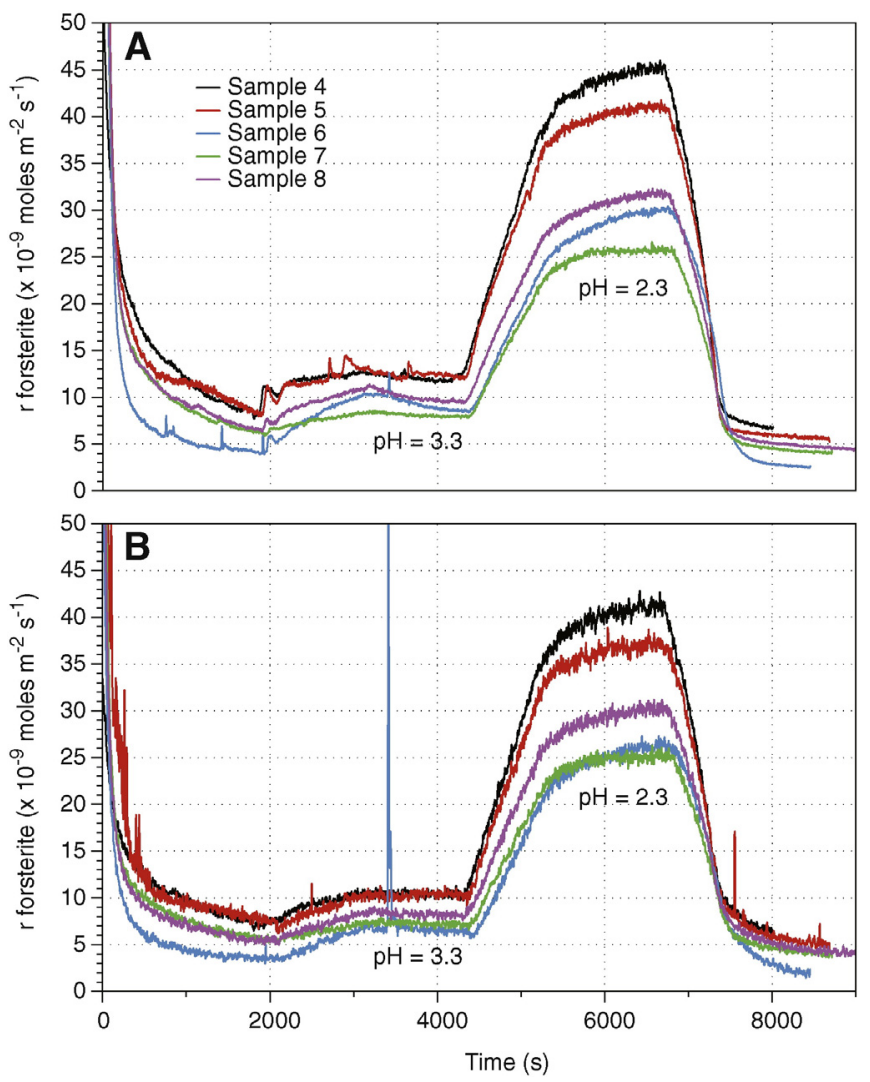

Fig. 8. Forsterite dissolution rates under varying $\mathrm{pH}$ estimated from time-resolved $\mathrm{Mg}$ (upper panel $\mathrm{A}$, calculated using the 5-point running $[\mathrm{Mg}]$ average, divided by 1.81 to take into account forsterite stoichiometry) and Si (lower panel B, calculated using the 5-point running [Si] average) concentration measured by on-line ICP-MS, multiplied by the eluent flow rate $\left(0.70 \pm 0.01 \mathrm{~mL} \mathrm{~min}^{-1}\right)$ and divided by the BET surface area for sample 4-8 (Table 2). Time-resolved eluent $\mathrm{pH}$ provided in Fig. 7B.

$V_{\mathrm{Si}(t)}=\Sigma \mathrm{Si}_{(t)} \times M V_{\text {forsterite }}$

where $M V_{\text {forsterite }}$ is the molar volume of forsterite $\left(43.79 \mathrm{~cm}^{3} \mathrm{~mol}^{-1}\right.$; Cemič, 2005), $V_{\mathrm{Mg}(t)}$ and $V_{\mathrm{Si}(t)}$ are the volumes of forsterite dissolved as a result of $\mathrm{Mg}$ and $\mathrm{Si}$ release, respectively (taking into account forsterite stoichiometry)

$Z_{\mathrm{Mg}(t)}=V_{\mathrm{Mg}(t)} / A$

$Z_{\mathrm{Si}(t)}=V_{\mathrm{Si}(t)} / A$

where $A$ is the surface area of the sample, $Z_{\mathrm{Mg}(t)}$ and $Z_{\mathrm{Si}(t)}$ are the thickness of the layer of forsterite dissolved by releasing $\mathrm{Mg}$ and $\mathrm{Si}$ respectively.

If the $\mathrm{Mg} / \mathrm{Si}$ ratio of the eluent is higher than the stoichiometry of forsterite, $Z_{\mathrm{Mg}(t)}>Z_{\mathrm{Si}(t)}$, and $Z_{\mathrm{Mg}(t)}-Z_{\mathrm{Si}(t)}$ is the thickness of the Mgleached surface layer at time $t$ (Fig. 9, assuming that the leached layer has lost $100 \%$ of its $\mathrm{Mg}$ and the molar volume of the silica layer has retained the molar volume of forsterite). If we assume that there is a linear $\mathrm{Mg} / \mathrm{Si}$ gradient in the leached layer, from zero at the top to forsterite stoichiometry at the bottom, estimated leached layer thicknesses would have to be doubled (Chou and Wollast, 1984). Although the calculated thickness is only an average over the entire surface area of the mineral and the assumption that the silica leached layer retains the molar volume of forsterite may not be correct (e.g. Kim et al., 2005), this simple calculation provides a useful visualization of the formation process of the leached layer (Fig. 9) and should estimate the true average thickness within a factor of $\sim 2$.

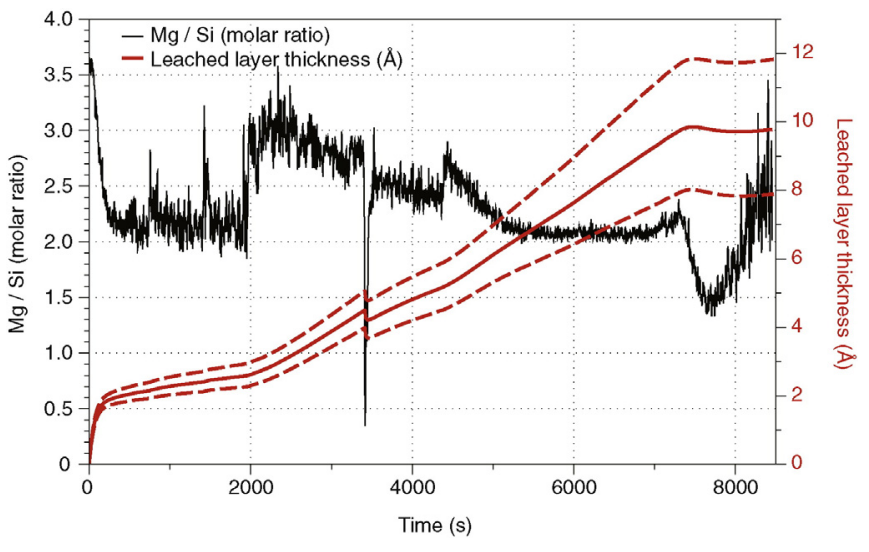

Fig. 9. Changes in the thickness of the Mg leached surface layer (solid red line) in sample 6 (thicknesses for samples 4, 5, 7, 8 are reported in suppl. Material). The dashed red lines represent range in $\mathrm{Mg}-\mathrm{Si}$ leached layer thickness calculated using the 95\% confidence interval of the forsterite stoichiometry $(\mathrm{Mg} / \mathrm{Si}=1.81 \pm 0.07) . \mathrm{Mg} / \mathrm{Si}$ molar ratio (calculated using the 5-point running [Mg, Si] average) is shown in black. Time resolved eluent $\mathrm{pH}$ is reported in Fig. 7B. (For interpretation of the references to color in this figure legend, the reader is referred to the web version of this article.)

The evolution of the leached layer thickness depends both on $\mathrm{Mg} / \mathrm{Si}$ and the rate of dissolution. The sample reported on Fig. 9 never reached stoichiometric dissolution $(\mathrm{Mg} / \mathrm{Si}=1.81)$ during the first $7000 \mathrm{~s}$ (117 $\mathrm{min}$ ) of the experiment, therefore the thickness of the leached layer continuously increased over that time period. If we assume that it lost all its Mg and remained isovolumetric, the Si-rich layer reached an apparent mean thickness of 2 ångströms within the first few minutes of dissolution in DIW and then deepened much more gradually to 3 ångströms during the following $30 \mathrm{~min}$ (Fig. 9; similar figures for the four other replicates are provided in the supplementary material). The rapid initial increase in thickness was due to the initially high $\mathrm{Mg} / \mathrm{Si}$ and dissolution rate, and the more gradual deepening that followed reflects near congruent dissolution and slower dissolution rates (Fig. 7A). At $\mathrm{pH}$ 3.3, the leached layer deepened faster because of higher dissolution rates and higher (but gradually decreasing) $\mathrm{Mg} / \mathrm{Si}$. At pH 2.3, $\mathrm{Mg} / \mathrm{Si}$ was closer to congruency but the much higher dissolution rates (Fig. 8) still resulted in a rapid increase in thickness, reaching a maximum of 10 ångströms at the end of the $\mathrm{pH} 2.3$ plateau. When reverting to DIW at the end of the dissolution sequence, the thickness of the leached layer decreased a little and stabilized, indicating a very slight erosion of Sirich layer, corresponding to eluent $\mathrm{Mg} / \mathrm{Si}$ below forsterite stoichiometry. This erosion was very small because the dissolution stoichiometry remained below that of forsterite for a short period only, at a time when the rate of dissolution was slow.

4.2.2.2. Sporadic exfoliation of the Si-rich layer. Brief but pronounced episodes of rapid Si release are observed during the dissolution of forsterite (Fig. 8B). The most prominent of these events was observed during the dissolution of sample 6, resulting in a sharp decrease in $\mathrm{Mg} / \mathrm{Si}$ (Fig. 9: $\mathrm{t}=3420 \mathrm{~s}(57 \mathrm{~min})$ ). These features are tentatively interpreted as sporadic exfoliations of a section of the Si-rich layer from which all the $\mathrm{Mg}$ had been previously stripped. The high temporal resolution afforded by the short eluent residence time in the reactor $(2.1 \mathrm{~s})$ and time-resolved ICP-MS analysis $(1.8 \mathrm{~s})$ provides interesting details on the most prominent exfoliation episode illustrated in Fig. 9, which lasted $\sim 20 \mathrm{~s}$, and is thus well documented by about 12 consecutive ICP-MS data points (Fig. 10). In particular, while Mg was not released above background during the peak of the exfoliation, a small Mg peak followed (Fig. 10B), possibly reflecting exposure of the new unaltered forsterite surface, which released $\mathrm{Mg}$ at a faster rate for a brief period.

FT-TRA data also provide a means of estimating the extent of exfoliation, within the constraints of a few simplifying assumptions. Fig. 10 indicates that the section exfoliated during this episode consisted 

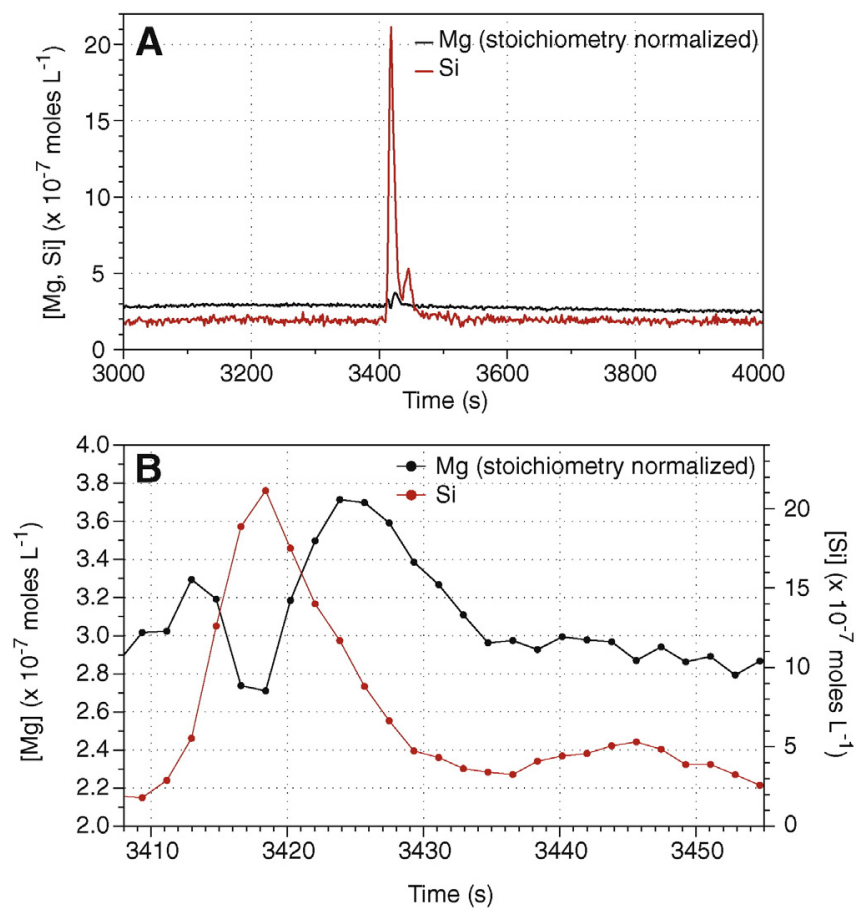

Fig. 10. A: Exfoliation event observed in sample 6 as an abrupt increase in [Si]. B: Same event on an expanded time scale showing the temporal sequence of changes in [Si] (yaxis on right) preceding a smaller $[\mathrm{Mg}]$ peak ( $\mathrm{y}$-axis on left).

exclusively of silica. Integrating the amount of silicon released above background during this event $2.8 \times 10^{-10}$ moles and assuming that the leached layer kept the molar volume of forsterite, we can calculate the volume of silica exfoliated $1.24 \times 10^{-8} \mathrm{~cm}^{3}$. Since we know the average thickness of the leached layer at the time of the exfoliation $4.5 \times 10^{-8} \mathrm{~cm}$, Fig. 9), the surface area of exfoliation can be calculated $\left(0.275 \mathrm{~cm}^{2}\right)$, which represents $8 \%$ of the total surface area of the sample. Exfoliation is triggered when the Si-enriched layer reaches a critical thickness (e.g. Jarvis et al., 2009) and has been attributed to molar volume differences between the forsterite crystal and the Si-enriched layer (e.g. Kim et al., 2005). Interestingly, the eluent generated by sample 6 also had the highest $\mathrm{Mg} / \mathrm{Si}$ molar ratio over the entire run, indicating the formation of a more extensive silica rich layer, which also resulted in a more pronounced decrease in $\mathrm{Mg} / \mathrm{Si}$ when raising the eluent $\mathrm{pH}$ back to 5.6. In contrast, sample 7 had the lowest $\mathrm{Mg} / \mathrm{Si}$ and released relatively little Si in the last transition to DIW (see supplementary information). This seems to indicate that the development of the surface Si-enriched layer differed among samples 4-8, even though they were treated under identical conditions. FT-TRA could thus also prove very useful to study the factors controlling exfoliation, which is a major process exposing fresh mineral surfaces necessary to optimize mineral carbonation and carbon sequestration (e.g. Béarat et al., 2006).

\section{Summary and future prospects}

The results from this exploratory study validate FT-TRA and on-line ICP-MS as a meaningful and versatile new experimental method to study mineral dissolution. We have identified a number of advantages, and several applications which could benefit from using this approach. The advantages are (1) faster attainment of steady state eluent concentration, which stems from the small reactor volume and extremely short residence time of the eluent in the reactor; (2) high temporal resolution resulting from the small volume of the reactor and on-line timeresolved ICP-MS analysis; and (3) simultaneous analysis of multiple elements occurring over a very wide range of concentrations ( $\mathrm{ppm}$ to $\mathrm{ppb}$ ). Several aspects relevant to mineral dissolution studies can benefit from these characteristics: (1) faster achievement of steady-state concentrations significantly accelerates the determination of dissolution rate parameters, allowing for replications and statistical analysis, and facilitating investigations of the influence of multiple variables; (2) hightemporal resolution documents abrupt (e.g. exfoliation) and gradual (e.g. leached surface formation, surface passivation) changes in dissolution rates and dissolution stoichiometry, which provide insight into dissolution processes and evolution; (3) simultaneous multi-element analysis over a wide range of concentrations facilitates the measurement of dissolution stoichiometry, including minor elements, and facilitates the study of slowly-dissolving minerals.

Regarding future prospects, one of the major limitations in quantifying intrinsic mineral dissolution rates is surface normalization, and it has been recently suggested that a paradigm shift may be required to effectively address this question (Lüttge et al., 2013). Nanoscale imaging of mineral surface topography (Atomic Force Microscopy (AFM) or Vertical Scanning Interferometry (VSI)) has revealed that mineral dissolution rates depend on the density of mineral surface features, such as steps, kinks and screw dislocations, which act as active surface sites (e.g. Ruiz-Agudo and Putnis, 2012). This insight lead to rationalizing the large range of dissolution rate constants, which have been carefully measured from bulk solution measurements, as reflecting stochastic changes in the surface density of these active sites. For more accurate descriptions, dissolution rates must therefore be adjusted to the number and reactivity of active surface sites. The solution proposed by Lüttge et al. (2013) is to replace dissolution rate constants by spectra of rate constants which would capture the variability in the energy level and density of active surface sites. If the density and types of active surface sites were amenable to predictive modeling and anchored to a bulk mineral property that can be measured to determine ab-initio conditions, this information could then be applied to any conditions in the laboratory or in the field. Progress will require combining different modeling and measurement techniques, in which FT-TRA could contribute significantly. As already demonstrated by Duckworth and Martin (2003), AFM can be combined with chemical analysis to simultaneously document changes in surface topography and bulk solution composition during mineral dissolution. The FT-TRA module presented here could be a perfect complement to surface imaging. The flow cell used in this study could be replaced by the flow-through cell used with AFM (Duckworth and Martin, 2003). The multiple data sets produced by this approach could help assess whether the evolution of reactive surface sites during mineral dissolution can be predicted and detected with the high temporal resolution and sensitivity afforded by FT-TRA/ ICP-MS to yield intrinsic dissolution rate constants normalized to active site distribution, possibly resolving the present surface normalization conundrum.

\section{Acknowledgments}

We acknowledge the very constructive input of two anonymous reviewers. Method development was made possible using a NSERC Research Tools and Instrumentation grant. The authors would like to acknowledge ongoing collaboration with the Pacific Centre for Isotopic and Geochemical Research (PCIGR) at the University of British Columbia, which allows for continuous method development.

\section{Appendix A. Supplementary data}

Supplementary data to this article can be found online at http://dx. doi.org/10.1016/j.chemgeo.2015.08.024.

\section{References}

Appelo, C.A.J., Postma, D., 2005. Geochemistry, groundwater and pollution. A.A. Balkema Publishers, Leiden, The Netherlands, p. 649. 
Béarat, H., McKelvy, M.J., Chizmeshya, A.V.G., Gormley, D., Nunez, R., Carpenter, R.W., Squires, K., Wolf, G.H., 2006. Carbon sequestration via aqueous olivine mineral carbonation: role of passivating layer formation. Environ. Sci. Technol. 40, 4802-4808.

Blum, A., Lasaga, A., 1988. Role of surface speciation in the low-temperature dissolution of minerals. Nature 331, 431-433.

Brantley, S.L., Chen, Y., 1995. Chemical weathering rates of pyroxenes and amphiboles. Rev. Mineral. Geochem. 31, 119-172.

Brunauer, S., Emmett, P.H., Teller, E., 1938. Adsorption of gases in multimolecular layers. J. Am. Chem. Soc. 60, 309-319.

Cemič, L., 2005. Thermodynamics in Mineral Sciences. Springer, Berlin Heidelberg, p. 399.

Chen, Y., Brantley, S.L., 2000. Dissolution of forsteritic olivine at $65{ }^{\circ} \mathrm{C}$ and $2<\mathrm{pH}<5$. Chem. Geol. 165, 267-281.

Chou, L., Wollast, R., 1984. Study of the weathering of albite at room temperature and pressure with a fluidized bed reactor. Geochim. Cosmochim. Acta 48, 2205-2217.

Colombani, J., 2008. Measurement of the pure dissolution rate constant of a mineral in water. Geochim. Cosmochim. Acta 72, 5634-5640.

De Baere, B., Molins, S., Mayer, K.U., François, R., 2015. Empirical determination of mineral dissolution regimes using flow-through time-resolved analysis (FT-TRA). Chem. Geol (submitted for publication).

Duckworth, O.W., Martin, S.T., 2003. Connections between surface complexation and geometric models of mineral dissolution investigated for rhodochrosite. Geochim. Cosmochim. Acta 67, 1787-1801.

Fischer, C., Kurganskaya, I., Schäfer, T., Lüttge, A., 2014. Variability of crystal surface reactivity: what do we know? Appl. Geochem. 43, 132-157.

Golubev, S.V., Pokrovsky, O.S., Schott, J., 2005. Experimental determination of the effect of dissolved $\mathrm{CO} 2$ on the dissolution kinetics of $\mathrm{Mg}$ and $\mathrm{Ca}$ silicates at $25^{\circ} \mathrm{C}$. Chem. Geol 217, 227-238

Grandstaff, D.E., 1986. The dissolution rate of forsterite olivine from Hawaiian beach sand. In: Colman, S.M., Dethier, D.P. (Eds.), Rates of Chemical Weathering of Rocks and Minerals. Academic Press, New York, pp. 41-59.

Haley, B.A., Klinkhammer, G.P., 2002. Development of a flow-through system for cleaning and dissolving foraminiferal tests. Chem. Geol. 185, 51-69.

Jarvis, K., Carpenter, R.W., Windman, T., Kim, Y., Nunez, R., Alawneh, F., 2009. Reaction mechanisms for enhancing mineral sequestration of $\mathrm{CO}_{2}$. Environ. Sci. Technol. 43, 6314-6319.

Kim, Y., Nunez, R., Carpenter, R.W., Chizmeshya, A.V.G., McKelvy, M.J., 2005. The nanoscale mechanism for San Carlos olivine carbonation. Microsc. Microanal. 11 (Suppl. 2), 1530-1531.
Lasaga, A., 1984. Chemical kinetics of water-rock interactions. J. Geophys. Res. 89, 4009-4025.

Liu, Y., Olsen, A.A., Rimstidt, J.D., 2006. Mechanism for the dissolution of olivine series minerals in acidic solutions. Am. Mineral. 91, 455-458.

Luce, R.W., Bartlett, R.W., Parks, G.A., 1972. Dissolution kinetics of magnesium silicates Geochim. Cosmochim. Acta 36, 35-50.

Lüttge, A., Arvidson, R.S., Fischer, C., 2013. A stochastic treatment of crystal dissolution kinetics. Elements 9, 183-188.

Olsen, A.A., 2007. Forsterite dissolution kinetics: applications and implications for chemical weathering, Ph.D. thesis, Virginia Polytechnic Institute and State Univ.

Olsen, A.A., Rimstidt, J.D., 2008. Oxalate-promoted forsterite dissolution at low pH. Geochim. Cosmochim. Acta 72, 1758-1766.

Olsson, J., Bovet, N., Makovicky, E., Bechgaard, K., Balogh, Z., Stipp, S.L.S., 2012. Olivine reactivity with $\mathrm{CO}_{2}$ and $\mathrm{H}_{2} \mathrm{O}$ on a microscale: implications for carbon sequestration. Geochim. Cosmochim. Acta 77, 86-97.

Pokrovsky, O.S., Schott, J., 2000a. Kinetics and mechanism of forsterite dissolution at $25^{\circ} \mathrm{C}$ and $\mathrm{pH}$ from 1 to 12. Geochim. Cosmochim. Acta 64, 3313-3325.

Pokrovsky, O.S., Schott, J., 2000b. Forsterite surface composition in aqueous solutions: a combined potentiiometric, electrokinetic, and spectroscopic approach. Geochim. Cosmochim. Acta 64, 3299-3312.

Rimstidt, J.D., 2015. Diffusion control of quartz and forsterite dissolution rates. Appl Geochem. 61, 99-108.

Rimstidt, J.D., Brantley, S.L., Olsen, A.A., 2012. Systematic review of forsterite dissolution rate data. Geochim. Cosmochim. Acta 99, 159-178.

Rosso, J.J., Rimstidt, J.D., 2000. A high resolution study of forsterite dissolution rates. Geochim. Cosmochim. Acta 64, 797-811.

Ruiz-Agudo, E., Putnis, C.V., 2012. Direct observations of mineral-fluid reactions using atomic force microscopy: the specific example of calcite. Mineral. Mag. 76, 227-253.

White, A.F., Peterson, M.L., 1990. Role of reactive-surface-area characterization in geochemical kinetic models. In: Melchior, D.C., Bassett, R.L. (Eds.), Chemical Modeling of Aqueous Systems II, American Chemical Society Symposium Series 419, 461-475.

Wogelius, R.A., Walther, J.V., 1991. Olivine dissolution at $25^{\circ} \mathrm{C}$ : Effects of $\mathrm{pH}, \mathrm{CO}_{2}$, and organic acids. Geochim. Cosmochim. Acta 55, 943-954. 